\title{
The effects of an active live yeast product on the growth performance of finishing lambs
}

\author{
G.H. Pienaar ${ }^{1}$, O.B. Einkamerer ${ }^{1 \#}$, H.J. van der Merwe' ${ }^{1}$, A. Hugo ${ }^{2}$, G.D.J. Scholtz ${ }^{1} \&$ \\ M.D. Fair ${ }^{1}$ \\ ${ }^{1}$ Department of Animal, Wildlife and Grassland Sciences; ${ }^{2}$ Department of Microbial, Biochemical and Food \\ Biotechnology; ${ }^{1,2}$ Faculty of Natural and Agricultural Sciences, University of the Free State, P.O. Box 339, \\ Bloemfontein 9300, South Africa
}

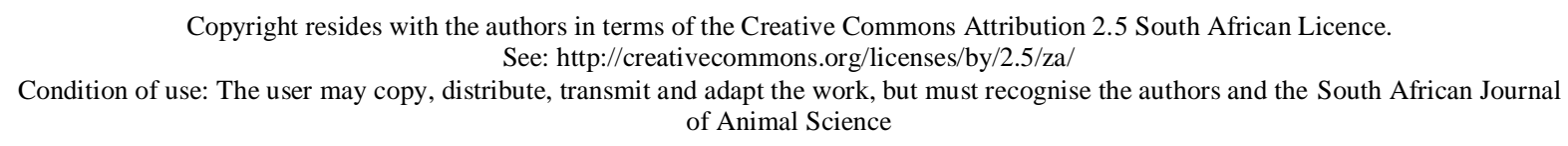

\begin{abstract}
A study was conducted to evaluate the effects of a rumen-specific, active live yeast (Saccharomyces cerevisiae; SC CNCM I-1077), alone or in combination with an ionophore (lasalocid-Na) in standard feedlot diets, on production performance and carcass quality of lambs. Sixty South African (S.A.) Mutton Merino lambs, weighing $25.7 \pm 2.2 \mathrm{~kg}$, were randomly allocated to four treatments (15 lambs per treatment) and further subdivided into five replicates per treatment (three lambs per replicate). The four dietary treatments consisted of an iso-nitrogenous and iso-energetic basal diet (177 g crude protein (CP)/kg dry matter (DM) and $276 \mathrm{~g}$ neutral detergent fibre (NDF)/kg DM) differing only in the additive included, i.e. (i) the control (C) diet (no additive), (ii) live yeast (SC) (220 g/ton), (iii) ionophore (G) (120 g/ton) and (iv) both live yeast with ionophore (SCG) at the same mentioned levels. After adaptation (8 days), the experimental diets were fed for 47 days in a finishing period. Feed intake and body weights were recorded weekly. At completion all animals were slaughtered $(44.5 \pm 3.8 \mathrm{~kg})$ and the cold $\left(2{ }^{\circ} \mathrm{C}\right)$ carcass weight and carcass characteristics recorded. Dietary treatment had no effect on feed intake, daily live weight gain, feed conversion ratio, carcass weight and carcass characteristics. Carcasses were leaner on the ionophore treatment $(\mathrm{G})$ in comparison to the control diet $(\mathrm{C})$. The results suggested that this rumen-specific live yeast included alone or in combination with an ionophore in finishing diets, containing less than $28 \% \mathrm{NDF} / \mathrm{kg} \mathrm{DM}$, did not affect performance and carcass traits of S.A. Mutton Merino lambs.
\end{abstract}

Keywords: Feedlot lambs, ionophore, live yeast

${ }^{\#}$ Corresponding author: Einkamererob@ufs.ac.za

\section{Introduction}

Ruminal fermentation has been manipulated to improve animal production with different feed additives, including microbial products and ionophores (Garcia et al., 2000). Additives are defined as substrates or preparations which, when incorporated in feedstuffs, influence or affect food characteristics, and improve animal production (Lyons, 1994).

Studies on ionophore antibiotics have shown that these additives can depress methane production (in vitro and in vivo) via a direct effect on rumen methanogens by shifting the fermentation pattern towards an increase in propionate at the expense of acetate (McDonald et al., 2002; Cheeke, 2005). Propionic acid is used more efficiently in metabolism than acetate and butyrate, with a reduced production of carbon dioxide and methane (Cheeke, 2005). The major ionophores used today are produced by various strains of Streptomyces fungi and include salinomycin, lysocellin, naracin, lasalocid and monensin (Cheeke, 2005). Additional to the positive effects on gain and feed efficiency, Cheeke (2005) showed that ionophores reduce lactic acidosis and feedlot bloat, aid in the control of coccidiosis and acute bovine pulmonary emphysema. Bergen \& Bates (1984) and Nagaraja (1995) also reported that the overall effectiveness of these compounds 
seem to be similar, but may vary depending on the dietary inclusion level, diet composition and various inherent animal factors.

Active dry yeast products (Saccharomyces cerevisiae being one of the most common) are well accepted as having beneficial effects in livestock production (Chaucheyras-Durand et al., 2008). Rumen specific yeasts (commonly referred to as probiotics) are also used to stimulate microbial activity in the rumen. A probiotic is defined as a live microbial food supplement that beneficially affects the host animal by improving the intestinal microbial balance (McDonald et al., 2002). In other words, the inclusion of probiotics in foods is designed to encourage certain strains of microbes in the gut at the expense of less desirable ones, unlike the destructive action of antibiotics. The main effects of live yeasts that have been identified are the improvement of rumen maturity, scavenging oxygen and maintaining the anaerobic conditions favouring microbial establishment (McDonald et al., 2002), stabilisation of ruminal pH (thus reducing the risk of acidosis by competing with lactic acid producing bacteria), increasing fibre degradation (efficiency of feed use) and interactions with plant cell-wall degrading micro-organisms (ChaucheyrasDurand et al., 2008). Rumen specific live yeasts may therefore aid in the faster adaptation and development of the rumen during weaning (Pinos-Rodriguez et al., 2008) and accordingly, faster adaptation of lambs exposed to feeding, ranging from extensive to intensive.

Due to the complexity of the ruminal ecosystem in terms of structure of microbial populations and activities, optimization of its function could be achieved by combinations of live yeast products and other additives to exert synergistic effects. Erasmus et al. (2005) found a modest complementary effect between yeast culture and monensin supplementation, as the yeast culture tended to alleviate the depression in mean DMI caused by monensin.

Data available on feeding active dry yeast products to small ruminants is limited, especially with regard to carcass characteristics (Titi et al., 2008). The aim of this study was to evaluate the effects of a rumen-specific, active live yeast (Saccharomyces cerevisiae; SC CNCM I-1077) alone or in combination with an ionophore (lasalocid-Na) in standard feedlot diets on the production performance and carcass quality of finishing lambs.

\section{Materials and Methods}

All procedures conducted during this study were approved by the Interfaculty Animal Ethics Committee for Animal Experimentation at the University of the Free State (Animal Experiment No. 08/09). Four dietary treatments $(880 \mathrm{~g} \mathrm{DM} / \mathrm{kg})$ were formulated and consisted of the same iso-nitrogenous and isoenergetic basal diet (177 g CP/kg DM and $276 \mathrm{~g} \mathrm{NDF} / \mathrm{kg} \mathrm{DM}$ ), differing in respect to the additive supplemented, i.e. (i) the control (C) diet (no additive), (ii) live yeast culture (SC) (220 g/ton), (iii) ionophore (G) (120 g/ton) and (iv) yeast and ionophore (SCG) included at the same levels as for treatments (ii) and (iii). Sixty S.A. Mutton Merino lambs, weighing $25.7 \pm 2.2 \mathrm{~kg}$, were randomly allocated to the four treatments (n $=15$ lambs per treatment). Each treatment group was subdivided into five replicates of three animals. The three lambs in each replicate were housed in pens $\left(2.808 \mathrm{~m}^{2}\right)$ on slatted floors in a well-ventilated building. Before the onset of the study, all animals were vaccinated with a 7-in-1 Clostridium spp. plus Pateurella spp. vaccine to aid in the build-up of active immunisation. The lambs were also dosed with a broad spectrum parasite remedy and injected with a trace mineral optimizer. All lambs had free access to clean, cool drinking water. During the adaptation stage of eight days, all lambs received lucerne hay milled through a $25 \mathrm{~mm}$ screen ad libitum for the first two days, and for the following six days, an iso-nitrogenous and iso-caloric adaptation diet containing $133 \mathrm{~g} \mathrm{CP} / \mathrm{kg}$ DM and $385 \mathrm{~g} \mathrm{NDF} / \mathrm{kg}$ DM. This ration contained the same dietary treatments as the experimental diets (i.e. C, SC, G and SCG). Thereafter, the experimental diets were fed for the remaining 47 days of the finishing period on an ad libitum basis. The feed intake and body weights were recorded weekly. Average daily feed intake, daily live weight gain (ADG) and feed conversion ratio (FCR) were calculated for the total finishing period (8-day adaptation period included; i.e. 55 days).

At the completion of the finishing period, all animals were slaughtered, and the cold $\left(2{ }^{\circ} \mathrm{C}\right)$ carcass weight and carcass characteristics recorded according to procedures described by Carson et al. (1999). Carcass evaluation was performed on the left side of each carcass. Carcasses were split between the $12^{\text {th }}$ and $13^{\text {th }}$ rib (thoracic vertebra) and fat depth measured $35 \mathrm{~mm}$ and $110 \mathrm{~mm}$ from the mid dorsal line. The mean back fat thickness was calculated accordingly. The external length, shoulder circumference and buttock circumference of each carcass were also measured. 
The data were analyzed and tested for significant differences according to a complete random design using the PROC ANOVA procedures of the SAS program (SAS, 1999). Animals were used as replicates. The honest Tukey test was used to test for significant differences between treatments.

\section{Results and Discussions}

The feed intake, performance and carcass characteristics of S.A. Mutton Merino lambs, as affected by different additives included in a standard feedlot diet, are presented in Table 1.

Table 1 The mean ( \pm SD) dry matter (DM) intake, daily gain and carcass characteristics of S.A. Mutton Merino lambs fed standard feedlot diets containing a rumen-specific live yeast and/or ionophore

\begin{tabular}{|c|c|c|c|c|c|c|}
\hline \multirow[b]{2}{*}{ Parameter } & \multicolumn{4}{|c|}{ Treatments } & \multirow{2}{*}{$\begin{array}{c}\text { Significance } \\
P \text {-value }\end{array}$} & \multirow[b]{2}{*}{$\mathrm{CV}$} \\
\hline & $\mathrm{C}$ & $\mathrm{SC}$ & G & SCG & & \\
\hline \multicolumn{7}{|l|}{ DM intake: } \\
\hline Adaptation diet (g/lamb/day) & $1383 \pm 179$ & $1370 \pm 92$ & $1373 \pm 92$ & $1277 \pm 165$ & 0.60 & 10.22 \\
\hline Finisher diet (g/lamb/day) & $1604 \pm 170$ & $1654 \pm 88$ & $1557 \pm 134$ & $1674 \pm 60$ & 0.44 & 7.43 \\
\hline \multicolumn{7}{|l|}{ Lamb performance: } \\
\hline Start live weight $(\mathrm{kg})$ & $25.7 \pm 2.2$ & $25.7 \pm 2.5$ & $25.7 \pm 2.4$ & $25.7 \pm 2.0$ & 1.00 & 8.88 \\
\hline End live weight (kg) & $43.8 \pm 3.5$ & $45.2 \pm 4.4$ & $43.6 \pm 4.5$ & $45.2 \pm 2.7$ & 0.54 & 8.69 \\
\hline $\mathrm{ADG}(\mathrm{g})$ & $330 \pm 64$ & $355 \pm 54$ & $327 \pm 74$ & $354 \pm 36$ & 0.41 & 17.23 \\
\hline FCR (kg) & $4.7 \pm 0.4$ & $4.5 \pm 0.2$ & $4.7 \pm 0.5$ & $4.5 \pm 0.3$ & 0.64 & 7.76 \\
\hline \multicolumn{7}{|l|}{ Carcass characteristics: } \\
\hline Cold carcass weight $(\mathrm{kg})$ & $22.4 \pm 1.7$ & $22.9 \pm 2.3$ & $21.9 \pm 2.5$ & $22.8 \pm 1.4$ & 0.50 & 8.98 \\
\hline Dressing percentage (\%) & $49.6 \pm 3.8$ & $50.7 \pm 5.1$ & $48.4 \pm 5.4$ & $50.3 \pm 3.2$ & 0.50 & 8.98 \\
\hline Carcass length $(\mathrm{cm})$ & $56.7 \pm 2.1$ & $57.5 \pm 2.4$ & $57.5 \pm 2.5$ & $57.5 \pm 2.2$ & 0.73 & 4.05 \\
\hline Shoulder circumference $(\mathrm{cm})$ & $75.8 \pm 1.8$ & $75.3 \pm 2.2$ & $75.1 \pm 2.7$ & $74.9 \pm 1.9$ & 0.74 & 2.88 \\
\hline Buttock circumference $(\mathrm{cm})$ & $64.2 \pm 2.5$ & $65.9 \pm 2.5$ & $64.0 \pm 2.3$ & $65.8 \pm 3.7$ & 0.14 & 4.30 \\
\hline Fat thickness $(\mathrm{mm})$ & $3.8^{\mathrm{a}} \pm 0.8$ & $3.6^{\mathrm{a}, \mathrm{b}} \pm 0.8$ & $2.9^{\mathrm{b}} \pm 0.7$ & $3.5^{\mathrm{a}, \mathrm{b}} \pm 1.0$ & 0.03 & 24.18 \\
\hline
\end{tabular}

${ }^{\mathrm{a}, \mathrm{b}}$ Means within rows with different superscripts differ significantly $(P<0.05) ; \mathrm{C}=$ control; $\mathrm{SC}=$ yeast; $\mathrm{G}=$ ionophore; $\mathrm{SCG}=$ yeast with ionophore; $\mathrm{CV}=$ coefficient of variation $(\%) ; \mathrm{ADG}=$ average daily gain $(\mathrm{g} / \mathrm{sheep} / \mathrm{day})$;

$\mathrm{FCR}=$ feed conversion ratio ( $\mathrm{kg} \mathrm{DM}$ feed intake/kg live weight gain).

No differences $(P>0.05)$ between treatments were observed regarding feed intake or any of the performance parameters (Table 1). In contrast, Chaucheyras-Durand et al. (2008) found that body weight gain in lambs improved using a diet with a yeast culture in combination with monensin. Although Erasmus et al. (1992) reported an increased DM intake by lactating dairy cows supplemented with a live yeast, Kawas et al. (2007) found that yeast culture had no positive effect on DM intake, live weight gain and FCR of finishing lambs.

Titi et al. (2008) noted that the feeding of a highly digestible concentrate diet, such as in the present study, could mask the positive effects of live yeast supplementation on ruminal $\mathrm{pH}$ and fibre digestion. The same could be said about a high fibre diet with a low forage quality. Haddad \& Goussous (2005) mentioned that results on the effects of yeast culture supplementation on production performance of ruminants are not consistent.

With the exception of fat thickness, carcass characteristics of the lambs were not affected $(P>0.05)$ by dietary treatment (Table 1). The findings of this study are in agreement with Titi et al. (2008) who found that active dry yeast supplementation had no effect on back fat thickness, intramuscular fat of the leg muscle, and weights and proportions of carcass cuts of finishing lambs. Ionophore inclusion in the diet reduced $(P<0.05)$ fat thickness on the carcasses of lambs. This effect, however, is cancelled when yeast was added to the finishing diet. Similarly, Murphy et al. (2003) found that ionophore supplementation reduced $(P<0.05)$ 
carcass back fat depth and dressing percentage of lambs, but had no effect on the other carcass traits measured. Smith \& Crouse (1984) explained that acetate provides $70 \%$ to $80 \%$ of the acetyl units for lipogenesis in subcutaneous fat, where glucose, whose precursor is propionate, was shown to provide $50 \%$ to $75 \%$ of the acetyl units in the intramuscular depot. Thus, manipulating the concentration of acetate and propionate in the rumen has potential in altering fat deposition, hence resulting in a leaner carcass at a specific slaughter weight. Ionophores have been proven to alter fatty acid concentrations in the rumen (Heydari et al., 2008).

\section{Conclusions}

The inclusion of a rumen active live yeast product or an ionophore in finishing diets for lambs had no effect $(P>0.05)$ on lamb growth performance and carcass characteristics. There was no complementary effect in terms of animal performance using a rumen active live yeast product in combination with an ionophore. The relative low fibre content $(<28 \% \mathrm{NDF})$ of the high energy finishing diet probably contributed to these findings.

\section{Acknowledgements} the study.

Vitam International and Nutri Feeds are acknowledged for their technical and financial support during

\section{References}

Bergen, W.G. \& Bates, D.B., 1984. Ionophores: Their effect on production efficiency and mode of action. J. Anim. Sci. 58, 1465-1483.

Carson, A.F., Moss, B.W., Steen, R.W.J. \& Kilpatrick, D.J., 1999. Effects of the percentage of Texel or Rouge de l'Ouest genes in lambs on carcass characteristics and meat quality. Anim. Sci. 69, 81-92.

Chaucheyras-Durand, F., Walker, N.D. \& Bach, A., 2008. Effects of active dry yeast on the rumen microbial ecosystem: Past, present and future. Anim. Feed. Sci. Technol. 145, 5-26.

Cheeke, P.R., 2005. Applied Animal Nutrition. Third edition. Pearson. Prentice-Hall, Upper Saddle River, New Jersey, USA.

Erasmus, L.J., Botha, P.M. \& Kistner, A., 1992. Effect of yeast culture supplement on production, rumen fermentation, and duodenal nitrogen flow in dairy cows. J. Dairy Sci. 75, 3056-3065.

Erasmus, L.J., Robinson, P.H., Ahmadib, A., Hinders, R. \& Garrett, J.E., 2005. Influence of prepartum and postpartum supplementation of a yeast culture and monensin, or both, on ruminal fermentation and performance of multiparous dairy cows. Anim. Feed. Sci. Technol. 122, 219-239.

Garcia, C.C.G., Mendoza, M.G.D., Gonzalez, M.S., Cobos, P.M., Ortega, C.M.E. \& Ramirez, L.R., 2000. Effect of a yeast culture (Saccharomyces cerevisiae) and monensin on ruminal fermentation and digestion in sheep. Anim. Feed. Sci. Technol. 83, 165-170.

Haddad, S.G. \& Goussous, S.N., 2005. Effect of yeast culture supplementation on nutrient intake, digestibility and growth performance of Awassi lambs. Anim. Feed. Sci. Technol. 118, 343-348.

Heydari, K.H., Dabiri, N., Fayazi, J. \& Roshanfekr, H., 2008. Effect of ionophores monensin and lasalocid on performance and carcass characteristics in fattening Arabi lambs. Pakistan J. Nutr. 7, 81-84.

Kawas, J.R., Garcia-Castillo, R., Garza-Cazares, F., Fimbres-Durazo, H., Olivares-Saenz, E., HernandezVidal, G. \& Lu, C.D., 2007. Effects of sodium bicarbonate and yeast on productive performance and carcass characteristics of light-weight lambs fed finishing diets. Small Rumin. Res. 67, 157-163.

Lyons, T.P., 1994. A panorama of techniques, processes and products today and tomorrow. In: Biotechnology in the feed industry. Eds Lyons, T.P. \& Jaques, K.A., Proceeding Alltech's $10^{\text {th }}$ Annual Symp. Loughborough, Leicestershire LE12 5RD, UK. pp. 1-48.

McDonald, P., Edwards, R.A., Greenhalgh, J.F.D. \& Morgan, C.A., 2002. Animal Nutrition. $6^{\text {th }}$ Edition. Pearson Prentice Hall, England.

Murphy, M.A., Zerby, H.N. \& Fluharty, F.L., 2003. The effects of energy source and ionophore supplementation on lamb growth, carcass characteristics and tenderness. Sheep Goat Res. J. 18, 89-95.

Nagaraja, T.J., 1995. Biotechnology in Animal Feeds and Animal Feeding. VCH Publishers Inc., N.Y., USA. 
Pinos-Rodriguez, J.M., Robinson, P.H., Ortega, M.E., Berry, S.E., Mendoza, G. \& Barcena, R.B., 2008. Performance and rumen fermentation of dairy calves supplemented with Saccharomyces cerevisiae 1077 or Saccharomyces boulardii 1079. Anim. Feed Sci. Technol. 140, 223-232.

SAS, 1999. SAS ${ }^{\circledR}$ User's Guide. Version 6.12. SAS Institute Inc., Cary, N.C., USA.

Smith, S.B. \& Crouse, J.D., 1984. Relative contributions of acetate, lactate and glucose to lipogenesis in bovine intramuscular and subcutaneous adipose tissue. J. Nutr. 114, 792-800.

Titi, H.H., Dmour, R.O. \& Abdullah, A.Y., 2008. Growth performance and carcass characteristics of Awassi lambs and Shami goat kids fed yeast culture in their finishing diet. Anim. Feed. Sci. Technol. 142, $33-43$. 